\title{
Lack of evidence for superantigen activity of Toxoplasma gondii towards human T cells
}

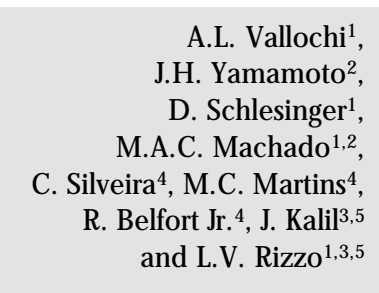

\author{
1Departamento de Imunologia, Instituto de Ciências Biomédicas, \\ 2Divisão de O ftalmologia, and 'Laboratório de Investigação M édica LIM 60, \\ Divisão de Alergia e Imunologia Clínica, Faculdade de Medicina, \\ Universidade de São Paulo, São Paulo, SP, Brasil \\ ${ }^{4}$ Departamento de O ftalmologia, U niversidade Federal de São Paulo, \\ São Paulo, SP, Brasil \\ 5Fundação E.J. Zerbini, São Paulo, SP, Brasil
}

\section{Correspondence}

L.V. Rizzo

Departamento de Imunologia

ICB, USP

Av. Prof. Lineu Prestes, 1730

055098-000 São Paulo, SP

Brasil

Fax: + 55-11-3818-7224

E-mail: Ivrizzo@ icb.usp.br

Research supported by FAPESP (No. 98/11205-0) and IPEPO.

L.V. Rizzo is the recipient

of a grant for scientific

productivity from $\mathrm{CN} \mathrm{Pq}$.

Received June 21, 2000

Accepted May 2, 2001

\section{Abstract}

Toxoplasma gondii is an obligatory intracellular parasite whose life cycle may include man as an intermediate host. More than 500 million people are infected with this parasite worldwide. It has been previously reported that $T$. gondii contains a superantigen activity. The purpose of the present study was to determine if the putative superantigen activity of $T$. gondii would manifest towards human $\mathrm{T}$ cells. Peripheral blood mononuclear cells (PBMC) from individuals with no previous contact with the parasite were evaluated for proliferation as well as specific Vß expansion after exposure to Toxoplasma antigens. Likewise, PBMC from individuals with the congenital infection were evaluated for putative Vß family deletions in their $\mathrm{T}$ cell repertoire. We also evaluated, over a period of one year, the PBMC proliferation pattern in response to Toxoplasma antigens in patients with recently acquired infection. Some degree of proliferation in response to $T$. gondii was observed in the PBMC from individuals never exposed to the parasite, accompanied by specific Vß expansion, suggesting a superantigen effect. However, we found no specific deletion of $\mathrm{V} \beta$ ( or $\mathrm{V} \alpha$ ) families in the blood of congenitally infected individuals. Furthermore, PBMC from recently infected individuals followed up over a period of one year did not present a reduction of the $\mathrm{VB}$ families that were originally expanded in response to the parasite antigens. Taken together, our data suggest that $T$. gondii does not have a strong superantigen activity on human $\mathrm{T}$ cells.

\section{Introduction}

Toxoplasmosis is caused by the intracellular protozoan, Toxoplasma gondii. Acquired disease may result in lymphadenopathy, low-grade fever, and sore throat. The disease often progresses to a symptomless
Key words

- Toxoplasma

- Tolerance

- Superantigen

- T cell receptor state in immunocompetent individuals $(1,2)$. In the immunocompromised host, encephalitis caused by the parasite may be fatal (3-6). Infection during pregnancy occurs in two of 1000 cases in the United States with up to a $50 \%$ transplacental infection rate, with a higher rate in other parts of the world $(2,7,8)$. 
Acquired disease was thought to be rare. However, several studies indicate that ocular lesions may be caused by $T$. gondii infection after birth (9-11).

Superantigens are molecules from microorganisms that can activate large numbers of $T$ cells. These molecules stimulate $T$ cells due to their ability to interact with the $T$ cell receptor (TCR) VB framework regions (12) and possibly with $\mathrm{V} \alpha$ elements (13). As a consequence of such promiscuous interactions, 2 to $30 \%$ of all $\mathrm{T}$ cells from one individual may be stimulated by some superantigens. The in vivo effects of such massive $\mathrm{T}$ cell stimulation are often deleterious (i.e., toxic shock syndrome and food poisoning in humans). Unlike conventional antigens, which are bound to the antigen-binding groove on MHC molecules, superantigens interact with MHC molecules outside the peptide-binding groove and do not require processing. Kappler and colleagues $(14,15)$ were the first to report superantigen activity. They described a strain-specific deletion of $T$ cells expressing a specific $V B$ in mice. The deletion was related to the presence of certain alleles of the minor histocompatibility loci. Minor histocompatibility locus products have been known for their ability to stimulate specific Vß-bearing $\mathrm{T}$ cells (1618). The cloning of these loci revealed that they were endogenous retroviruses of the mouse mammary tumor virus family and that various family members bind to different Vß domains $(12,19,20)$. Others have reported that staphylococcal enterotoxins (21) and products from Yersinia pseudotuberculosis (22), Streptococcus (23), and Mycoplasma also displayed superantigen-like activities (24). In addition, viruses such as rabies (25), Epstein Barr virus, and cytomegalovirus (26) express superantigens. Protozoans (Plasmodium falciparum) were also reported to contain components with superantigen properties (27).

Recently, $T$. gondii was also suggested to contain a component with superantigen ac- tivity $(28,29)$. These authors showed that naive CD8+ cells bearing the VB5.1 were stimulated in the presence of the whole parasite. This finding is of particular importance since it has also been suggested that superantigens might be involved in triggering autoimmune diseases. There is an ongoing discussion in the ophthalmic literature regarding a possible role for autoimmunity in patients with recurrent ocular lesions following infection with $T$. gondii. Therefore, we set out to establish whether in humans the most common effects of a superantigen were detected following exposure to $T$. gondii or its antigens. We were able to demonstrate that $\mathrm{T}$ cells from some non-exposed individuals did proliferate in response to antigens of the parasite. Furthermore, there were expanded specific $\mathrm{V} ß$ families. In addition, when the peripheral blood mononuclear cells (PBMC) from individuals with congenital disease were analyzed some deletions were observed in the $\mathrm{T}$ cell repertoire. These data suggest that indeed $T$. gondii has a superantigen that does activate and delete human $T$ cells. On the other hand, when T cells from seronegative individuals were stimulated in vitro with $T$. gondii antigens, expansion was not followed by deletion of specific $\mathrm{V} B$ families. Furthermore, the deletions of TCR VB families observed in patients with congenital toxoplasmosis were shared among their kindred, even those that were not infected by the parasite. Since deletion of responding cells is a hallmark of superantigen activity, we suggest that, although there is some evidence for a superantigen activity in $T$. gondii, it is not likely that such activity affects human cells.

\section{Material and Methods}

\section{Patients}

Blood samples were collected from 36 individuals who had negative antibody (IgM and $\mathrm{IgG}$ ) titers for $T$. gondii (less than 1:4), 
48 seropositive individuals (IgG titers above $1: 16$ ), and 11 patients with congenital toxoplasmosis. Antibody titers were determined with a test kit from Sigma Chemical Co. (St. Louis, MO, USA). The patients studied were 19 and 56 years old and came from Erechim or São Paulo, Brazil. All gave informed consent to participate in the study. The clinical status (congenital ocular toxoplasmosis or absence of ocular lesions) of the individuals evaluated was determined as previously described $(9,11,30)$. Briefly, patients were considered to have congenital toxoplasmosis when their mother had a positive IgM response to Toxoplasma antigens that developed during pregnancy and when ocular lesions were visualized by fundoscopy on the occasion of their first visit to the ophthalmologist. None of the individuals studied were under treatment with any immunosuppressive or immunomodulatory drug. Women using oral anticonceptives were not included in this study since previous unpublished results from our group indicate that they may alter the antigen-specific response patterns of $\mathrm{T}$ cells. Other drugs being used by the patients during the study were antibiotics (2 patients), aspirin (2 patients), acetaminophen (3 patients) and antihistamine (5 patients). Patients with acute toxoplasmosis were diagnosed by their clinical features (malaise, lymphadenopathy and sore throat) and based on positive IgM titers to Toxoplasma antigens. All procedures were approved by the Ethics Committee of the institutions where the patients were being followed up (UNIFESP, USP).

\section{Proliferation assays}

Proliferation assays were performed as described previously (31). Briefly, PBMC obtained by gradient centrifugation were diluted to $10^{6}$ cells $/ \mathrm{ml}$ and added to 96 -flatbottom well microtiter plates (Falcon). Cultures were stimulated with $2.5 \mu \mathrm{g} / \mathrm{ml}$ of phytohemagglutinin (PHA) or $5 \mu \mathrm{g} / \mathrm{ml}$ of soluble toxoplasma tachyzoite antigen (STAg) or control antigens (tuberculin purified protein derivative (PPD) or tetanus toxoid), in a final volume of $200 \mu \mathrm{l}$ of RPMI 1640 per well containing $5 \% \mathrm{AB}+$ human serum pooled from blood donors. PBMC were cultured for $96 \mathrm{~h}$ and then pulsed with $0.5 \mu \mathrm{Ci}\left[\mathrm{H}^{3}\right]-$ thymidine per well and processed accordingly for standard gaseous or liquid scintillography. Results are presented as stimulation index units that represent the mean proliferation in cpm in response to a given stimulus divided by the mean background proliferation of unstimulated cells. Stimulation indices above two were considered positive. PBMC were obtained from blood drawn at least one month after the last active episode of disease and before two months had elapsed from that episode.

\section{Soluble tachyzoite antigen preparation}

STAg was prepared as described previously (32). Briefly, tachyzoites of the RH strain were maintained by in vitro passage in human foreskin fibroblasts at $37^{\circ} \mathrm{C}$. For antigen preparation, tachyzoites were harvested from fibroblast cultures, passed through a 27-gauge needle, centrifuged at $70 \mathrm{~g}$ for 5 min and pelleted at $590 \mathrm{~g}$ for $10 \mathrm{~min}$. Tachyzoites were then sonicated 4 times for $20 \mathrm{~s}$ each round and centrifuged at $10,000 \mathrm{~g}$ for $30 \mathrm{~min}$. The supernatant preparation termed STAg was used as antigen in the in vitro assays.

\section{Flow cytometry}

Standard flow cytometry analysis was performed using antibodies against human $\mathrm{V} \alpha$ and $\mathrm{V} \beta$ chain from Endogen (Cambridge, MA, USA) or from PharMingen (San Diego, CA, USA). One million cells were stained directly in a final volume of $100 \mu \mathrm{l}$ PBS according to manufacturer instructions and read with a FACScan (Becton-Dickinson Immunocytometry Systems, San Jose, CA, 
USA) using the Lysis II program or a FACScallibur instrument (Becton-Dickinson) using the CellQuest program.

\section{Reverse transcriptase-polymerase chain reaction (RT-PCR) analysis of the VB TCR chain}

TCR analysis by RT-PCR was performed as described previously (33). RNA from PBMC was obtained using the RNAzol B method, reverse transcribed and amplified using primers described elsewhere (33). PCR products were separated on $1.5 \%$ agarose gels and analyzed by Southern blot hybridization with fluorescein-labeled internal probes using the ECL-3' oligolabeling and detection system and Hyperfilm-ECL (Amersham Pharmacia Biotech, Little Chalfont, UK).

\section{Reagents}

Isolymph was purchased from GallardSchlesinger (Cale Place, NY, USA). PHA-p was obtained from Difco Laboratories (Detroit, MI, USA). Interleukin (IL)-2 was purchased from Boehringer-Mannheim Corp. (Mannheim, Germany), and human IL-4 and IFN- $\alpha$ were purchased from Genzyme Diag-

Figure 1. PBMC proliferation in response to STAg. The box plot presents the proliferation of PBMC from 36 seronegative individuals and 48 individuals with previous contact with Toxoplasma gondii (seropositive). The data are expressed as stimulation index (SI). The seronegative individuals had a median $( \pm S D)$ proliferation of $1.1 \pm 2.4$. The median SI for the seropositive group was $11.5 \pm$ 28.7. The mean SI of STAg for the two groups was 2.3 and 20.9, respectively. The average SI of PHA in the groups was 29.8 and 30.1,

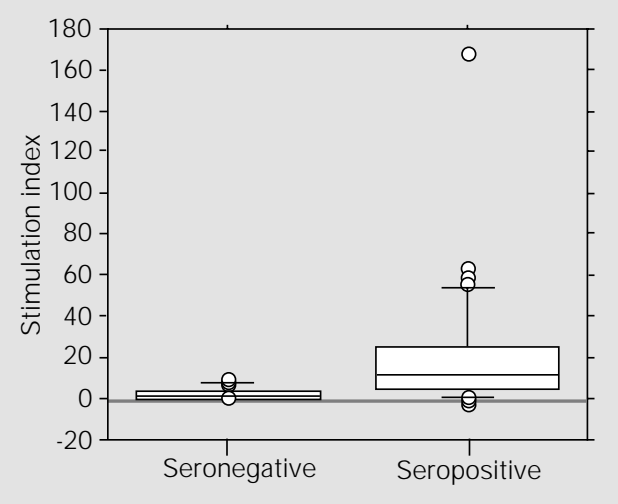

respectively (proliferation was measured at $48 \mathrm{~h}$ and antigen-specific proliferation at $96 \mathrm{~h}$ ). The average SI of PPD in the groups was 10.6 and 12.1, respectively. The average SI of tetanus toxoid in the groups was 9.9 and 10.0, respectively. PBMC, peripheral blood mononuclear cells; STAg, soluble toxoplasma tachyzoite antigen; PHA, phytohemagglutinin; PPD, tuberculin purified protein derivative. nostics (Cambridge, MA, USA). Human IL-1, IL-12 and TNF- $\alpha$ were obtained from R\&D Systems (Minneapolis, MN, USA), and human IL-10 and IL-5 were from PharMingen.

\section{Statistical analysis}

Data were analyzed by ANOVA Fisher PLSD and by the Kruskal-Wallis test for nonparametric data. Results were considered statistically different when a $95 \%$ confidence level was achieved.

\section{Results}

In a recent population-based household survey performed in Erechim, Southern Brazil, $184(17.7 \%)$ of 1042 individuals examined were considered to have ocular toxoplasmosis $(9,11)$. Because of the high frequency of the disease, its occurrence in multiple siblings, and its low prevalence in children as compared to the adult population, many of the ocular toxoplasmosis cases in Erechim are thought to be sequelae of postnatal infection (10).

Here we studied the immune response against Toxoplasma antigens from patients that have been followed by some of us (Silveira C and Belfort Jr R, unpublished data). Patients were divided into three groups: a) normal controls with negative serology for $T$. gondii, matched to the other groups for sex and age, b) patients with positive serology for $T$. gondii but without ocular lesions, and c) patients with congenital toxoplasmosis. In addition, we studied six patients who had recently acquired toxoplasmosis and followed their lymphocyte proliferative response to $T$. gondii antigens and the pattern of $\mathrm{V} \alpha$ and $\mathrm{V} \beta$ expression of their lymphocytes following stimulation with STAg.

Figure 1 shows the stimulation indices (SI) obtained when PBMC from seronegative and seropositive individuals were cultured in the presence of STAg. Although 
some seronegative individuals had positive proliferative responses $(=2 \mathrm{SI})$, most of them did not respond to Toxoplasma antigens. In contrast, PBMC from seropositive individuals proliferated significantly in response to STAg irrespective of the presence of ocular lesions. There was no difference between groups in response to PHA or unrelated antigens (PPD and tetanus toxoid).

Because PBMC from some individuals in the seronegative group showed an in vitro response to $T$. gondii antigens, it was suggested that a superantigen activity was at play. Therefore, we decided to analyze PBMC from patients with congenital toxoplasmosis for deletions of specific $\mathrm{V} ß$-bearing lymphocytes. Those individuals were more likely to carry deletions since they had been exposed to the parasite antigens for the longest period of time. The presence of $\mathrm{V} \beta$ families was tested by flow cytometry when antibodies were available or by RT-PCR for the VB families against which antibodies were not available. Deletions of Vß3, Vß12, Vß14 and Vß15 were observed (Figure 2). One patient had a deletion of VB5.1 cells, less than $0.5 \%$ by flow cytometry (data not shown). However, most patients did not show any gaps in their Vß repertoire. The VB deletions found in patients with congenital toxoplasmosis were often shared by noninfected members of the same family, suggesting that these were familial variations not due to the nature of Toxoplasma infection. However, it is still possible that deletion of STAg-specific $T$ cells does occur and the methods used to evaluate TCR V $\alpha$ and $V \beta$ families are not sensitive to detect minor changes in these families.

Studies on mice have suggested that $T$. gondii contains a superantigen-like activity capable of selective induction of $\mathrm{T}$ cells bearing the VB5 chain both in vitro and in vivo $(28,29)$. Because superantigen stimulation causes expansion, followed by deletion of the T cells bearing the TCR with which they interact, we hypothesized that if $T$. gondii expresses a superantigen, exposure to STAg would result in the expansion of $\mathrm{T}$ cells bearing specific $V B$ in seronegative individuals. Therefore, we stimulated PBMC from seronegative individuals with STAg. Five days after stimulation, the $\mathrm{V} \alpha$ and $\mathrm{V} \beta$ repertoire in culture was evaluated by flow cytometry in comparison to the $\mathrm{V} \alpha$ and $\mathrm{V} \beta$ repertoire expressed by unstimulated cells. $\mathrm{A} V \alpha$ or $\mathrm{V} \beta$ was considered expanded if the percentage of positive cells after stimulation was at least two times higher than its frequency in the unstimulated population. Nine out of 26 seronegative individuals showed an expansion of some $T$ cells bearing the VB5.1 receptor (Table 1). Increases in the percentage of $\mathrm{T}$ cells expressing VB5.2/ Vß5.3, Vß6.7, Vß7.1, Vß8, Vß9 and Vß23 were also found. One patient showed a significant expansion of $V \alpha 12.1$-bearing cells. The fact that $T$ cells from unexposed individuals proliferate in response to STAg does support the hypothesis that a superantigen expressed by $T$. gondii is capable of stimulating human $\mathrm{T}$ cells. This hypothesis is further supported by the finding that such proliferation occurs through the expansion of specific Vß-bearing $T$ cells. Interestingly, one of the VB families that is found to be expanded in patients after stimulation with

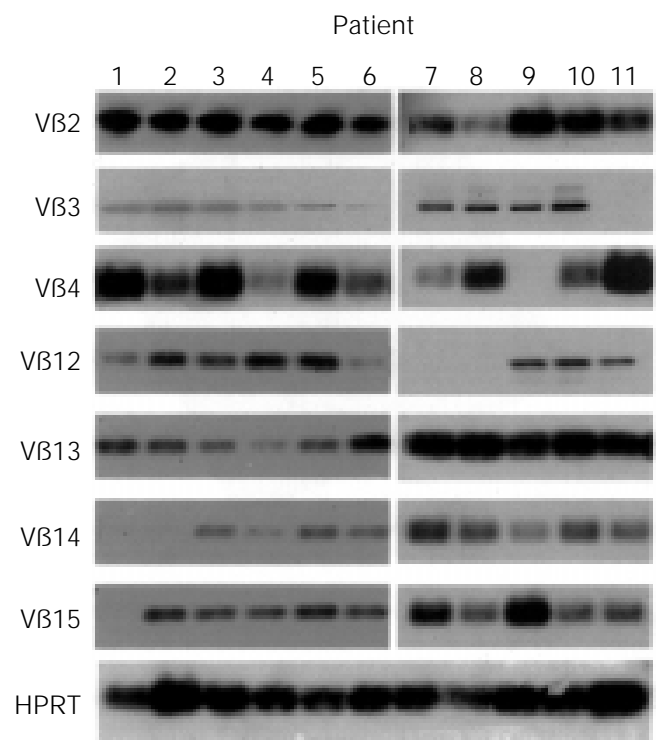

Figure 2. Peripheral blood mononuclear cell expression of $V B$ families as measured by RTPCR. Patients with congenital ocular toxoplasmosis (1 to 11 ) were evaluated for the presence of the Vß families shown. Hypoxanthine phosphoribosyltransferase (HPRT) was used as a housekeeping gene control. 
Table 1. VB expression in peripheral blood mononuclear cells from seronegative individuals after stimulation with soluble toxoplasma tachyzoite antigen (STAg).

\begin{tabular}{|c|c|}
\hline Patient \# & Vß enhanced \\
\hline 1 & Vß5.1 (50\%) \\
\hline 2 & Vß5.2Nß5.3 and Vß9 (150 and 148\%, respectively) \\
\hline 3 & none \\
\hline 4 & none \\
\hline 5 & Vß5.1 (200\%) \\
\hline 6 & none \\
\hline 7 & Vß5.1 and Vß8 (210 and 167\%, respectively) \\
\hline 8 & none \\
\hline 9 & Vß5.1 and Vß7 (202 and 135\%, respectively) \\
\hline 10 & VB5.1 and VB6.7 (154 and 195\%, respectively) \\
\hline 11 & V $\alpha 12.1(149 \%)$ \\
\hline 12 & none \\
\hline 13 & VB5.1 and Vß5.2NB5.3 (102, 183 and $190 \%$, respectively) \\
\hline 14 & Vß9 $(163 \%)$ \\
\hline 15 & Vß23 $(102 \%)$ \\
\hline 16 & none \\
\hline 17 & Vß7.1 (111\%) \\
\hline 18 & none \\
\hline 19 & Vß6.7 and Vß9 (123 and 200\%, respectively) \\
\hline 20 & Vß5.1 (157\%) \\
\hline 21 & Vß5.1 (132\%) \\
\hline 22 & Vß5.1 and Vß6.7 (173 and 229\%, respectively) \\
\hline 23 & none \\
\hline 24 & VB5.1 and VB7.1 (139 and 213\%, respectively) \\
\hline 25 & Vß5.1 and Vß9 (166 and 191\%, respectively) \\
\hline 26 & none \\
\hline
\end{tabular}

$\mathrm{V} \alpha$ or Vß was considered to be enhanced if the number of positive cells after exposure to STAg was at least double the number of cells bearing the same V $\alpha$ or VB in cultures without stimulation. Percent increase in expression of $\mathrm{V} \alpha$ or $\mathrm{VB}$ over expression in unstimulated cells is shown in parentheses.
STAg is the same that is found to be expanded in response to Toxoplasma stimulation in the mouse (32). However, we found no evidence of specific $\mathrm{V} B$ family expansion in ex vivo PBMC from individuals with congenital ocular toxoplasmosis, acquired ocular toxoplasmosis, or asymptomatic seropositive individuals (data not shown).

Because we found a degree of Vß-specific $\mathrm{T}$ cell expansion in response to STAg in naive donors, we decided to investigate the evolution of the $\mathrm{T}$ cell response to Toxoplasma antigens in individuals recently infected with $T$. gondii. We studied six individuals who presented positive IgM titers to T. gondii with classic symptoms of acute infection (see Material and Methods). The first three patients have been followed up for over a year, three additional patients have been followed up for different periods of less than 240 days. Figure 3 shows that proliferation in response to STAg does not seem to decrease over the period of time the patients were evaluated. Furthermore, flow cytometry analysis of the $\mathrm{V} \alpha$ and $\mathrm{V} \beta$ expanded upon STAg stimulation of the PBMC from these patients showed that no families were deleted over the study period (Table 2 ).
Figure 3. PBMC proliferation from six patients in response to PHA (filled line and open symbols), STAg (dotted line and closed symbols) and PPD (thick filled line and open symbols). Each symbol represents the proliferation over time of one given patient. The standard error is shown for each point. PHA-stimulated proliferation was measured at $48 \mathrm{~h}$ and antigen-specific proliferation at $96 \mathrm{~h}$. Proliferation data are presented as stimulation index (mean cpm with the stimulus divided by the cpm obtained in culture without the stimulus). For abbreviations, see legend to Figure 1.

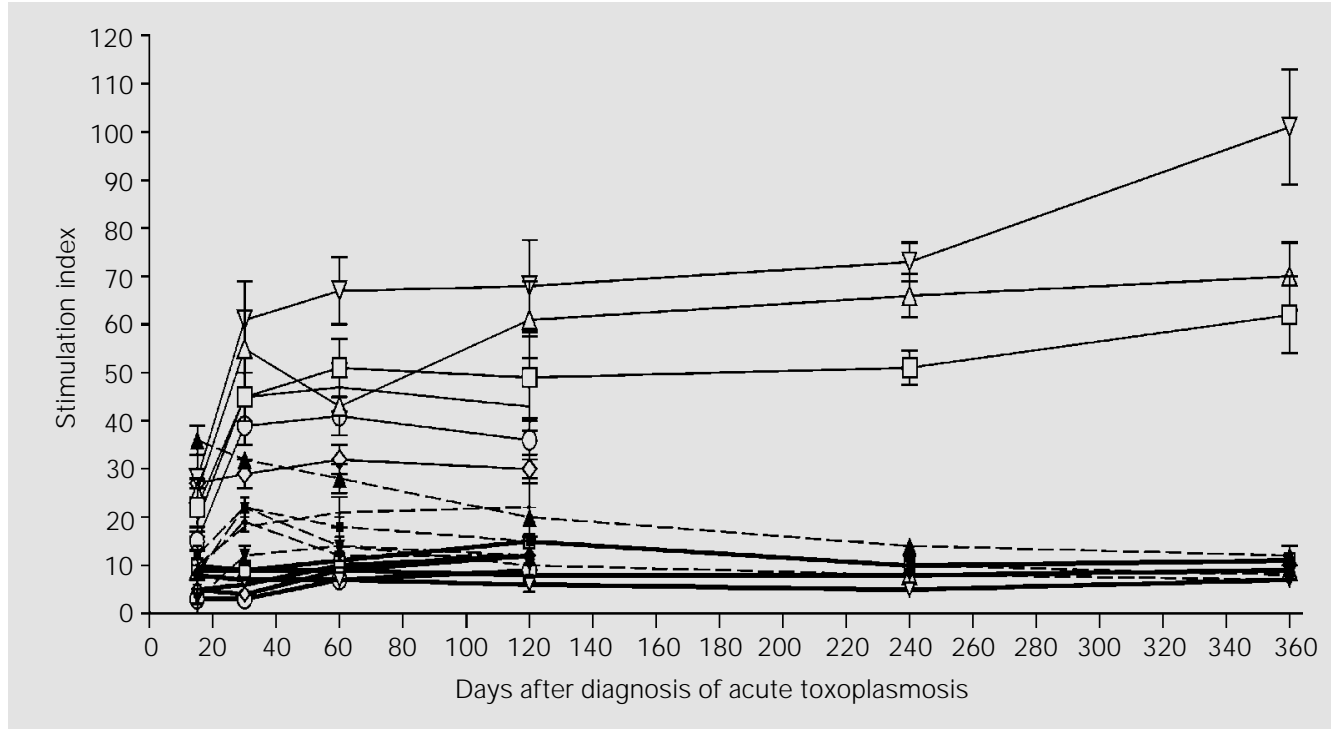


Table 2. Flow cytometry analysis of the V $\alpha$ and Vß expression by peripheral blood mononuclear cells from patients with acute toxoplasmosis after stimulation with soluble toxoplasma tachyzoite antigen (STAg).

\begin{tabular}{|c|c|c|c|c|}
\hline Patient & V $\alpha$ or Vß expanded ( 15 days) & V $\alpha$ or Vß expanded (60 days) & V $\alpha$ or Vß expanded (120 days) & $V \alpha$ or $V ß$ expanded (360 days) \\
\hline 1 & $\begin{array}{c}\text { Vß9 (103\%), VB8 (101\%), } \\
\text { Vß5.1 (87\%) }\end{array}$ & $\begin{array}{l}\text { Vß9 (98\%), VB8 (105\%), } \\
\text { Vß5.1 (97\%), V } 22(55 \%)\end{array}$ & $\begin{array}{l}\text { Vß9 }(100 \%), \text { Vß8 }(75 \%), \\
\text { Vß5.1 }(105 \%), \operatorname{V\alpha 2}(55 \%)\end{array}$ & $\begin{array}{l}\text { Vß9 (98\%), Vß8 (105\%), } \\
\text { Vß5.1 (97\%), V } 22(55 \%)\end{array}$ \\
\hline 2 & Vß6.7 (107\%), Vß9 (75\%) & $\begin{array}{c}\text { Vß6.7 }(101 \%), \text { Vß9 }(85 \%), \\
\text { Vß8 }(63 \%)\end{array}$ & $\begin{array}{l}\text { Vß6.7 (107\%), Vß9 (75\%), } \\
\text { Vß8 (43\%), V } 22(45 \%)\end{array}$ & $\begin{array}{c}\text { Vß6.7 (97\%), } \\
\text { Vß9 }(55 \%), \text { Vß8 (73\%) }\end{array}$ \\
\hline 3 & Vß7.1 (112\%) & $\begin{array}{c}\text { VB7.1 (103\%), } \\
\text { VB5.2NB5.3 (95\%) }\end{array}$ & $\begin{array}{l}\text { VB7.1 (105\%), } \\
\text { VB5.2NB5.3(101\%) }\end{array}$ & $\begin{array}{c}\text { VB7.1 (98\%), } \\
\text { VB5.2NB5.3(109\%) }\end{array}$ \\
\hline 4 & Vß8 (120\%), Vß5.1 (95\%) & Vß8 (120\%), Vß5.1 (95\%) & $\begin{array}{c}\text { VB8 }(150 \%), \text { VB5.1 (105\%), } \\
\text { VB13 }(57 \%)\end{array}$ & NT \\
\hline 5 & VB3.1 (101\%), Vß23 (75\%) & Vß3.1 (101\%), Vß23 (75\%) & $\begin{array}{c}\text { VB3.1 }(101 \%) \text {, VB23 }(75 \%), \\
\text { VB3 }(62 \%), \text { VB2 }(43 \%)\end{array}$ & NT \\
\hline 6 & Vß13 (100\%), Vß7.1 (65\%) & Vß13 (98\%), Vß7.1(85\%) & Vß13 (111\%), Vß7.1 (33\%) & NT \\
\hline
\end{tabular}

V $\alpha$ or VB was considered to be enhanced if the number of positive cells after exposure to STAg was at least double the number of cells bearing the same $V \alpha$ or $V B$ in cultures without stimulation. Percent increase in expression of $V \alpha$ or Vß over expression in unstimulated cells is shown in parentheses. NT: not tested; these patients were followed up for a shorter period of time.

Taken together, these data do not support the hypothesis that $T$. gondii bears a superantigen that acts on human lymphocytes.

\section{Discussion}

The possibility that $T$. gondii carries a superantigen has been extensively discussed in the literature $(28,29,34)$. Aside from its scientific significance, this information also carries important clinical implications. If confirmed, these findings could shed light on a number of clinical idiosyncrasies observed in some patients with Toxoplasma chorioretinitis, such as the number of recurrences and the inconstant response to corticosteroids. It may also help to explain why patients with the congenital form of the disease have a decreased immune response to the parasite's antigens.

We have shown that PBMC from more than one third of the individuals with no previous contact with $T$. gondii proliferated in the presence of Toxoplasma antigens. These data would confirm that the parasite contains a superantigen capable of stimulat- ing human T cells. However, when the same cells were analyzed for $\mathrm{V} ß$-specific deletions we were unable to detect any deletion of Vß families. Since superantigen stimulation always results in the deletion of the proliferating $\mathrm{T}$ cells, these conflicting results suggest that proliferation induced by STAg in these "naive" individuals may be due to some other cause rather than superantigenic stimulation. To further evaluate the question of specific $V ß$ family deletions after stimulation with STAg, we studied the T cell repertoire of individuals with congenital toxoplasmosis. These studies revealed that 11 of 36 of these individuals presented specific $V ß$ deletions (gaps) in their $T$ cell repertoire. However, their siblings as well as other members of the family also showed the same deletions irrespective of their status regarding the infection or contact with $T$. gondii. These results suggest that the inability to respond to Toxoplasma antigens by patients with congenital toxoplasmosis cannot be explained on the basis of $T$ cell repertoire gaps caused by superantigenic stimulation over a prolonged period of time (35). Fi- 
nally, when we analyzed the evolution of the $\mathrm{T}$ cell immune response to STAg in patients recently infected with $T$. gondii, we were unable to show any changes in the $V ß$ families they express. It is possible that the methods used to analyze $\mathrm{T}$ cell deletion (flow cytometry and PCR) were not sensitive enough to detect minor changes in the $T$ cell repertoire. Nevertheless, the literature indicates that changes induced by a superantigen are usually easily detected by such methods $(36,37)$.

Taken together, our data strongly suggest that $T$. gondii does not contain a superantigen capable of stimulating human lymphocytes. However, if a superantigen is not responsible for the stimulation induced by STAg in naive cells, why do they proliferate? A distinct possibility is the cross-reactivity between Toxoplasma antigens and a previously encountered antigen. $T$ cells that react to Toxoplasma have been reported to recognize other parasites $(35,38,39)$. It remains to be investigated which antigen or antigens might be involved in the individuals evaluated in this study. The seronegative volunteers had an unremarkable clinical history, without any uncommon infectious episodes, suggesting that the antigen(s) is(are) of a common nature, either from another microorganism or from environmental sources such as food. It is of interest that, whatever the cross-reactive antigen might be, it does not stimulate a humoral response. This would not be a first since a similar situation has been reported for Chagas' disease (40). In Chagas' disease, lymphocytes from normal individuals used as controls responded with proliferation and cytokine production following stimulation with the Trypanosoma cruzi antigen protein B13.

We suggest that $T$. gondii does not have a superantigen that stimulates human $T$ cells. We also suggest that cross-reactivity is responsible for the lymphocyte proliferation observed in response to $T$. gondii in seronegative patients.

\section{References}

1. Fishback J L \& Frenkel J K (1991). Toxoplasmosis. Seminars in Veterinary Medicine and Surgery (Small Animal), 6: 219226.

2. Frenkel J K (1985). Toxoplasmosis. Pediatric Clinics of North America, 32: 917-932.

3. Bertoli $F$, Espino M, Arosemena JRT, Fishback J L \& Frenkel J K (1995). A spectrum in the pathology of toxoplasmosis in patients with acquired immunodeficiency syndrome. Archives of Pathology and Laboratory Medicine, 119: 214-224.

4. Mitchell WG (1999). Neurocysticercosis and acquired cerebral toxoplasmosis in children. Seminars in Pediatric Neurology, 6: 267-277.

5. Zumla A \& Croft SL (1992). Chemotherapy and immunity in opportunistic parasitic infections in AIDS. Parasitology, 105 (Suppl): S93-S101.

6. Suzuki Y, Wong SY, Grumet FC, Fessel J , Montoya J G, Zolopa AR, Portmore A Schumacher-Perdreau $F$, Schrappe $M$, Koppen S, Ruf B, Brown BW \& Remington J S (1996). Evidence for genetic regulation of susceptibility to toxoplasmic en- cephalitis in AIDS patients. J ournal of Infectious Diseases, 173: 265-268.

7. Brezin AP, Kasner $L$, Thulliez $P, L i Q$, Daffos F, Nussenblatt RB \& Chan CC (1994). Ocular toxoplasmosis in the fetus. Immunohistochemistry analysis and DNA amplification. Retina, 14: 19-26.

8. Smith JL (1999). Foodborne infections during pregnancy. J ournal of Food Protection, 62: 818-829.

9. Glasner PD, Silveira C, Kruszon-M oran D, Martins MC, Burnier J unior M, Silveira S, Camargo ME, Nussenblatt RB, Kaslow RA $\&$ Belfort J unior R (1992). An unusually high prevalence of ocular toxoplasmosis in southern Brazil. American J ournal of Ophthalmology, 114: 136-144.

10. Nussenblatt RB \& Belfort J r R (1994). Ocular toxoplasmosis. An old disease revisited (clinical conference) (published erratum appears in J AMA 1994 Aug 3, 272 (5): 356) (see Comments). J ournal of the American Medical Association, 271: 304307.

11. Silveira C, Belfort J $r$ R, Burnier J r M \& Nussenblatt R (1988). Acquired toxoplas- mic infection as the cause of toxoplasmic retinochoroiditis in families. American J ournal of Ophthalmology, 106: 362-364.

12. Pullen AM, Bill J, Kubo RT, Marrack $P \&$ Kappler J W (1991). Analysis of the interaction site for the self superantigen Mlsla on $T$ cell receptor $V$ beta. J ournal of Experimental Medicine, 173: 1183-1192.

13. Locksley RM (1997). Exploitation of immune and other defence mechanisms by parasites: an overview. Parasitology, 115: S5-S7.

14. Kappler J W, Wade T, White J , Kushnir E, Blackman M, Bill J , Roehm N \& Marrack P (1987). A T cell receptor $V$ beta segment that imparts reactivity to a class II major histocompatibility complex product. Cell, 49: 263-271.

15. Kappler J W, Staerz U, White J \& Marrack PC (1988). Self-tolerance eliminates T cells specific for MIs-modified products of the major histocompatibility complex. Nature, 332: 35-40.

16. Huber BT (1992). M Is superantigens: how retroviruses influence the expressed $T$ cell receptor repertoire. Seminars in Im- 
munology, 4: 313-318.

17. Marrack P, Kushnir E \& Kappler J (1991). A maternally inherited superantigen encoded by a mammary tumour virus (see Comments). Nature, 349: 524-526.

18. Herman A, Kappler J W, Marrack P \& Pullen AM (1991). Superantigens: mechanism of T-cell stimulation and role in immune responses. Annual Review of Immunology, 9: 745-772.

19. Dyson PJ, Knight AM, Fairchild S, Simpson E \& Tomonari K (1991). Genes encoding ligands for deletion of $\mathrm{V}$ beta 11 $T$ cells cosegregate with mammary tumour virus genomes (see Comments). Nature, 349: 531-532.

20. Woodland DL, Lund FE, Happ MP, Blackman MA, Palmer E \& Corley RB (1991). Endogenous superantigen expression is controlled by mouse mammary tumor proviral loci. J ournal of Experimental Medicine, 174: 1255-1258.

21. Herman A, Labrecque N, Thibodeau J, Marrack P, Kappler J W \& Sekaly RP (1991). Identification of the staphylococcal enterotoxin A superantigen binding site in the beta 1 domain of the human histocompatibility antigen HLA-DR. Proceedings of the National Academy of Sciences, USA, 88: 9954-9958.

22. Stuart PM \& Woodward JG (1992). Yersinia enterocolitica produces superantigenic activity. J ournal of Immunology, 148: 225-233.

23. Tomai M, Kotb M, Majumdar G \& Beachey EH (1990). Superantigenicity of streptococcal M protein. J ournal of Experimental Medicine, 172: 359-362.

24. Cole BC, Kartchner DR \& Wells DJ (1989). Stimulation of mouse lymphocytes by a mitogen derived from Mycoplasma arthritidis. VII. Responsiveness is associated with expression of a product(s) of the $\mathrm{V}$ beta 8 gene family present on the $T$ cell receptor alpha/beta for antigen. J ournal of Immunology, 142: 4131-4137.

25. Lafon M, Scott-Algara D, Marche PN, Cazenave PA \& J ouvin-Marche E (1994). Neonatal deletion and selective expansion of mouse $T$ cells by exposure to rabies virus nucleocapsid superantigen. J ournal of Experimental Medicine, 180: 12071215.

26. Dobrescu D, Ursea B, Pope M, Asch AS \& Posnett DN (1995). Enhanced HIV-1 replication in $\mathrm{V}$ beta $12 \mathrm{~T}$ cells due to human cytomegalovirus in monocytes: evidence for a putative herpesvirus superantigen. Cell, 82: 753-763.

27. Yao Z, MaraskovskyE, Spriggs MK, Cohen Jl, Armitage RJ \& Alderson MR (1996). Herpesvirus saimiri open reading frame 14, a protein encoded by $T$ lymphotropic herpesvirus, binds to $\mathrm{MHC}$ class II molecules and stimulates $T$ cell proliferation. J ournal of Immunology, 156: 3260-3266.

28. Denkers EY, Caspar P \& Sher A (1994). Toxoplasma gondii possesses a superantigen activity that selectively expands murine $\mathrm{T}$ cell receptor $\mathrm{V}$ beta 5 -bearing CD8+ lymphocytes. Journal of Experimental Medicine, 180: 985-994.

29. Denkers EY, Caspar $P$, Hieny $S \&$ Sher $A$ (1996). Toxoplasma gondii infection induces specific nonresponsiveness in lymphocytes bearing the $V$ beta 5 chain of the mouse T cell receptor. J ournal of Immunology, 156: 1089-1094.

30. Yamamoto JH, Vallochi AL, Silveira $C$, Filho J K, Nussenblatt RB, Cunha-Neto E, Gazzinelli RT, Belfort J $r$ R \& Rizzo LV (2000). Discrimination between patients with acquired toxoplasmosis and congenital toxoplasmosis on the basis of the immune response to parasite antigens. J ournal of Infectious Diseases, 181: 20182022.

31. Corrêa-Sales C, Tosta CE \& Rizzo LV (1997). The effects of anesthesia with thiopental on $\mathrm{T}$ lymphocyte responses to antigen and mitogens in vivo and in vitro. International J ournal of Immunopharmacology, 19: 1177-1128.

32. Gazzinelli RT, Bala $S$, Stevens R, Baseler M, Wahl L, Kovacs J \& Sher A (1995). HIV infection suppresses type 1 lymphokine and IL-12 responses to Toxoplasma gondii but fails to inhibit the synthesis of other parasite-induced monokines. J ournal of Immunology, 155: 1565-1574.
33. Cunha-Neto E, Moliterno R, Coelho V Guilherme L, Bocchi E, Higuchi MDL, Stolf N, Pileggi F, Steinman L \& Kalil J (1994). Restricted heterogeneity of T cell receptor variable alpha chain transcripts in hearts of Chagas' disease cardiomyopathy patients. Parasite Immunology, 16: 171-179.

34. Sher A, Denkers EY \& Gazzinelli RT (1995). Induction and regulation of host cell-mediated immunity by Toxoplasma gondii. Ciba Foundation Symposium, 195: 95-104 (Discussion 104-9).

35. Curiel TJ , Krug EC, Purner MB, Poignard P \& Berens RL (1993). Cloned human CD4+ cytotoxic $T$ lymphocytes specific for Toxoplasma gondii lyse tachyzoite-infected target cells. J ournal of Immunology, 151: 2024-2031.

36. Abe J, Kotzin BL, J ujo K, Melish ME, Glode MP, Kohsaka T \& Leung DY (1992). Selective expansion of $T$ cells expressing T-cell receptor variable regions $\mathrm{V}$ beta 2 and $\mathrm{V}$ beta 8 in Kawasaki disease. Proceedings of the National Academy of Sciences, USA, 89: 4066-4070.

37. Van Parijs L, Refaeli $Y$, Abbas AK \& Baltimore D (1999). Autoimmunity as a consequence of retrovirus-mediated expression of C-FLIP in lymphocytes. Immunity, 11: 763-770.

38. Fuchs N, Sonda K, Butikofer $P$ \& Hemphill A (1999). Detection of surface-associated and intracellular glycoconjugates and glycoproteins in Neospora caninum tachyzoites. International J ournal of Parasitology, 29: 1597-1611.

39. Bjerkas I, J enkins MC \& Dubey J P (1994). Identification and characterization of $\mathrm{Ne}$ ospora caninum tachyzoite antigens useful for diagnosis of neosporosis. Clinical and Diagnostic Laboratory Immunology, 1: 214-221.

40. Abel LC, Kalil J \& Cunha Neto E (1997). Molecular mimicry between cardiac myosin and Trypanosoma cruzi antigen B13: identification of a B13-driven human $\mathrm{T}$ cell clone that recognizes cardiac myosin. Brazilian J ournal of Medical and Biological Research, 30: 1305-1308. 